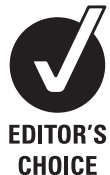

CHOICE

\title{
Gainfully employed? An inquiry into bidi-dependent livelihoods in Bangladesh
}

\author{
Anupom Roy, ${ }^{1}$ Debra Efroymson, ${ }^{2}$ Lori Jones, ${ }^{3}$ Saifuddin Ahmed, ${ }^{4}$ Islam Arafat, ${ }^{4}$ \\ Rashmi Sarker, ${ }^{4}$ Sian FitzGerald ${ }^{3}$
}

${ }^{1}$ Department of Anthropology, Macquarie University, New South Wales, Australia ${ }^{2}$ HealthBridge Foundation of Canada, Dhaka, Bangladesh ${ }^{3}$ HealthBridge Foundation of Canada, Ottawa, Canada ${ }^{4}$ WBB Trust, Dhaka, Bangladesh

\section{Correspondence to}

Anupom Roy, Department of Anthropology, Macquarie University, North Ryde, New South Wales, 2109, Australia; anupom.roy@mq.edu.au

Received 17 January 2011 Accepted 22 June 2011

Published Online First

20 July 2011

\section{ABSTRACT}

Objectives This study sought to increase government, civil society and media attention to the tobacco-poverty connection in Bangladesh, particularly as it relates to bidi-dependent livelihoods.

Data sources This study consisted of a literature review that examined the socioeconomic impacts of tobacco farming, the working conditions of tobacco workers and the impact of tobacco on consumers, and a primary research study among bidi workers and users. The research included in-depth and semistructured interviews and focus group discussions among bidi workers and a closed-ended quantitative survey among bidi users. Data synthesis Most bidi worker families earn about $\$ 6.40$ per 7-day work week, leaving them below the poverty line. The majority of bidi workers are women and children, classified as unpaid assistants, who toil long hours in toxic environments. Bidi users are primarily low-income earners who spend up to $10 \%$ of their daily income on bidis; the average proportion of income spent on bidis decreased as income increased. If bidi expenditures were reduced and spent instead on food or local transportation, many higher value jobs could be created. This could also mean better health and nutrition for those currently engaged in bidi work.

Conclusions The results of this study illustrate the linkages between tobacco and poverty. Tobacco control is not simply about health and the environment, but also about the living conditions of the poorest of the poor. If we are to improve the lives of the poor, we must address the root causes of poverty, which include the production and use of tobacco.

\section{INTRODUCTION}

Tobacco industry studies initially focused on the 'business' of tobacco production and sale, paying little attention to the industry's true economic value. One of the earliest economic analyses of tobacco ${ }^{1}$ explored the 'historical development of the cigarette industry and its market structure and market behavior'.2 More recent studies, however, demonstrate that tobacco production and use adversely affect the socioeconomic conditions of low-income earners in particular and that tobaccorelated costs vastly exceed economic returns such as employment or taxes. ${ }^{3-7}$ Tobacco has been shown to be 'a net economic disaster' because of its multifaceted negative impacts. ${ }^{8}$

Comprehensive analyses of the tobacco industry's economic contribution in low- and middleincome countries argue that decreased tobacco consumption would not harm national economies, as increases in other sectors would offset financial losses in the tobacco sector. ${ }^{9} 10$ Studies assessing the impact of price and income on consumption behaviour demonstrate that price responsiveness is greatest among the socioeconomically disadvantaged and that the poor gain the greatest economic benefit from reduced tobacco consumption. ${ }^{11-20}$ Such studies support the use of tax increases as part of a cost-effective strategy to reduce tobacco use.

Some governments-particularly in lower income countries-use employment and tax revenue arguments to justify their unwillingness to take stronger steps against tobacco, ${ }^{21} 22$ even while acknowledging its harmful health impacts. ${ }^{23}$ For instance, Bangladeshi legislators recently refused to raise taxes on bidis ${ }^{i}$ because of concerns that employment losses and increased taxes would unduly harm the poor and increase poverty. ${ }^{24}$ It has been demonstrated, however, that low tax policies actually increase tobacco expenditures among the very poor. ${ }^{3}$ Thus, because high prices are a deterrent to tobacco use, low taxes could be considered regressive as they encourage the poor to use tobacco.

To counter employment loss arguments, researchers have examined the potential impact on employment of shifting spending from tobacco to other products. ${ }^{25-27}$ Their investigations suggest that if tobacco consumption falls, employment losses would be offset: "when consumers spend less on tobacco they tend to spend money on other products instead', ${ }^{26}$ which in turn would result in more jobs in other sectors. Furthermore, any evaluation of the tobacco industry's contribution to employment must consider much more than the number of jobs generated. In Bangladesh, for example, much has been written about the quality and nature of labour-intensive bidi production-particularly its exploitation of children. ${ }^{28-31}$

Bidi-related employment includes tobacco farmers, bidi makers and those involved in distribution and sales. As bidi tobacco powder is prepared from plant roots and low-quality leaves, ${ }^{28}$ a negligible number of farmers grow tobacco solely for bidis, while people engaged in distributing and selling bidis work with many goods. Bidi makers comprise the majority of bidi-related employment in Bangladesh. The Bangladesh Bureau of Statistics estimates the number of bidi workers at $266818,{ }^{32}{ }^{33}$ while the tobacco industry claims to employ 2.5 million in bidi making. Even if it was to include the entire family of each worker,

'Bidis are small unfiltered, hand-rolled cigarettes sold in packs of 25; being far cheaper than conventional cigarettes, they are a popular form of smoking among the poor in Bangladesh. 
the industry's figure-10 times larger than the official estimate-appears significantly exaggerated: total employment in all manufacturing industries, including the large textiles and ready-made garments industry, is only 6.9 million. ${ }^{34}$ To better understand the nature of bidi-related livelihoods, Work for a Better Bangladesh recently examined the socioeconomic value of bidi making and possible alternate employment generation.

\section{Objectives}

The primary objective of this study was to increase government, civil society and media attention to the tobacco-poverty connection in Bangladesh, particularly as it relates to bidi-dependent livelihoods.

\section{METHODS}

The researchers first conducted a literature review of the socioeconomic impacts of tobacco farming, tobacco labourers' working conditions and the impact of tobacco spending on consumers. The term 'tobacco' was used in combination with the terms poverty, employment, farming, bidi, beedi, smoking, smoker and Bangladesh in Google Scholar to identify relevant online literature. This produced five online peer-reviewed journal articles specific to Bangladesh. Articles published by national and international organisations were acquired directly.

The researchers visited the libraries of local and international organisations and consulted with independent scholars working on tobacco in Bangladesh. They also reviewed legislative documents to assess the extent to which the issue of tobacco and poverty had been addressed. Of the collected documents, 16 articles and books were particularly relevant to the Bangladeshi context; many others provided an international context.

The literature review was supplemented by a primary research study conducted between August and December 2009. Two groups of informants were addressed: bidi workers and bidi users, ${ }^{\text {ii }}$ the former in two Bangladeshi districts (Rangpur and Kushtia) and the latter in an additional four (Meherpur, Natore, Cox's Bazar and Bandarban). The sites were selected to ensure wide geographical variation and to incorporate the main bidi factories. Bidi workers included men, women and children working on factory premises and/or from home. Bidi users included those who were observed smoking at local roadside tea stalls. The researchers approached prospective informants, explained the study's purpose and asked them to participate in the respective surveys. All prospective informants were approached while they were alone to ensure that that their decisions to participate were not influenced by the presence of others. Those who agreed were added to the study until the desired number of participants in each category was reached.

In-depth interviews were held with four bidi factory supervisors while semistructured interviews were held with 20 bidi workers, all using an ethnographic approach and interview guides prepared by the research team. The interviews explored the informants' perceived costs and benefits of bidi production. Two informal focus group discussions of six persons each were then held with the representatives of the bidi workers to clarify issues arising from the interviews. All data obtained were thematically organised and analysed. ${ }^{35}$

The research team administered a short closed-ended quantitative survey among 2590 bidi users to assess their daily earnings, bidi smoking expenses and expenditure on daily household

\footnotetext{
ii Tobacco farmers were also a key informant group during the study but are not discussed in this paper.
}

goods. Only male bidi users were interviewed, as previous studies show negligible smoking rates among Bangladeshi women. $^{36} 37$

\section{RESULTS AND KEY FINDINGS Labour, remuneration and financial return}

Two major categories of workers are involved in the bidi-making process, all employed with oral contracts. First are those who collect tobacco plant roots and other materials, slice them into small pieces and prepare the masala (tobacco mixture). These workers are paid about US\$1.17iii (80 taka) per day. Usually, the masala preparation takes place 5 days a week and the worker is paid the equivalent of $\$ 5.83$ (400 taka) weekly or $\$ 23.31$ (1600 taka) monthly.

Bidi rollers are paid based on the number of bidis made, which in turn is dependent on assigned 'serial numbers'-official factory permission to make bidis. For example, if a worker receives 10000 serial numbers, he must produce 10000 bidis per day. The minimum and maximum daily serial numbers allocated are 10000 and 14000 , respectively, for each of the 4 days per week that the factories are open. Depending on the location, payment for each 1000 bidis produced ranges from $\$ 0.16$ (11 taka) to $\$ 0.24$ (17 taka); this includes preparing the thosh ${ }^{\text {iv }}$ filling them with masala and packaging the bidis. The bidi worker earns $\$ 6.40$ (440 taka) to $\$ 13.44$ (952 taka) per week, ${ }^{\mathrm{v}}$ or a maximum of $\$ 53.76$ per month.

Although the factories run only 4 days per week, to meet their quota the contracted worker's entire family is often involved in bidi making at home, working up to $15 \mathrm{~h}$ per day, 7 days per week. ${ }^{\mathrm{vi}}$ Thus, the maximum $\$ 53.76$ earned per month is the entire family's income. Most families earn no more than $\$ 25.60$, getting paid at the lower end of the scale and receiving daily quotas of 10000 . The impact of this, in terms of livelihood, is significant: most bidi workers are included in the $40 \%$ of the Bangladeshi population living below the international poverty line of $\$ 1.25$ per day. ${ }^{39}$

The situation is even worse given that many workers do not receive serial numbers directly from the factory. For example, in Rangpur, although factory owners pay $\$ 0.30$ (21 taka) for each 1000 bidis produced but middlemen ${ }^{\text {vii }}$ take $\$ 0.14$ (10 taka), leaving the remaining $\$ 0.16$ (11 taka) to be divided among the bidi rollers. Meanwhile, the selling price of a pack of 25 bidis is $\$ 0.08$ (6 taka); of the $\$ 3.49$ (240 taka) the company receives for each 1000 bidis rolled, the workers retain only $4.6 \%$, often split among several workers. ${ }^{\text {viii }}$

Although some men were observed working in the factories, the majority of bidi workers are women and children classified as unpaid assistants. The observed involvement of women and

\footnotetext{
iiiThe 24 October 2009 exchange rate used during this research was 1 USD $=68.64$ taka. ${ }^{38}$

ivThosh are cylindrical papers that are rolled and filled with tobacco powder.

'The minimum amount is calculated as $\$ 0.16 \times 10$ packages of 1000 bidis (10000 serial numbers) $\times 4$ days; the maximum amount is calculated as $\$ 0.24 \times 14$ packages of 1000 bidis (14000 serial numbers) $\times 4$ days.

viAlthough men are typically the only registered factory workers who receive contracts to make bidis, in many cases, an individual is unable to fulfil his contract and must recruit family members to help. Wives and other family members thus 'assist' the men to meet their contractual deadlines.

vii Middlemen own the serial numbers and sell them to the workers. Obtaining serial numbers from the bidi factories in Rangpur requires a $\$ 145.70$ (10 000 taka) deposit, so very few people are able to do so. The involvement of middlemen in the process increases the vulnerability of the workers.

viiiF For each 1000 bidis, 40 packs of 25 are sold at 6 taka each, netting the company 240 taka. For each 1000 bidis produced, the worker receives 11 taka. Therefore, 11 taka (worker remuneration)/240 taka (company revenue) $=4.6 \%$.
} 
children bidi rollers working for little or no pay is supported by earlier studies. ${ }^{29} 3940$ Sometimes neighbours are subcontracted. Wives of contracted bidi workers complained about having to neglect household tasks to make thosh, in order to pay less to non-family hired workers. However, since women's household work is considered to have little or no economic value ${ }^{41}$ taking time away from it to earn a few cents was noted by participants as a worthwhile use of women's time. The women were nonetheless expected to finish their household work.

Children are typically expected to 'help' as well and often accompany their fathers to the factories. A previous study highlighted the exploitation of child labour in Bangladesh's bidi industry, wherein parents' socioeconomic problems were imposed on their children, who were forced to drop their schooling to work. ${ }^{29}$ During this study, the researchers noted that many bidi factories displayed signs declaring 'No undereighteen workers are employed here' even as large numbers of young children were observed working inside. The signs may have been installed because government laws prohibit children employment. During interviews, factory supervisors stated that these children were only 'helpers' to their employed parents.

\section{Work environment}

Bidi factory ventilation systems were observed and reported by the workers to be extremely poor. For the researchers, the most significant impression came from the dark and toxic surroundings. During interviews conducted outside the factory premises, workers said that the factory maintained a scant ventilation system designed not to protect the workers but to reduce neighbourhood complaints about the smell. The bidi-rolling rooms contained only one or two windows-which always faced the inside of the factory, not the outdoors-to help suppress the dust and strong smell that arise especially from the tobacco powder. ${ }^{42}$ In addition to improper ventilation, another strong first impression upon entering the factories was the harsh, irritating smell that came from the masala room. Less than a few minutes in the masala room left one researcher vomiting and another with a headache that lasted for hours. The masala room was one of the few well-lit rooms. The workers did not have adequate respiratory protection, only covering their faces with a thin cloth.

Those rolling bidis at home fare little better, sitting for long periods in the same position. Their continuous exposure to tobacco dust causes various health complications, including respiratory and skin diseases, loss of appetite, lethargy, backache, headache and general pain. These observations corroborate results from previous studies, which demonstrated that Bangladeshi and Indian bidi workers toiled in unhygienic environments with less than optimal sanitation and ventilation facilities. ${ }^{43-52}$ The researchers did not find any studies that have investigated the type and health effects of chemicals used in the bidi-making process.

\section{Bidi users' income and expense on bidis}

The survey data showed that bidi users are primarily lowincome earners. ${ }^{\text {ix }}$ Among those participating in the study, 29\% were farmers, $29 \%$ rickshaw pedallers or bicycle cart drivers, $14 \%$ daily labourers and 10\% hawkers. The remaining 18\% reported

\footnotetext{
${ }^{i x}$ Virtually all bidi users are poor. There is a very strong social segmentation of the market that causes people to look down on those who smoke bidis. Many of the very poor, while mostly smoking bidis, also smoke cigarettes, but virtually nobody who can afford cigarettes would smoke bidis.
}

Table 1 Daily expenditure on bidis according to the reported level of daily income

\begin{tabular}{llll}
\hline $\begin{array}{l}\text { Daily income } \\
\text { (taka) }\end{array}$ & $\begin{array}{l}\text { Daily expenditure on } \\
\text { bidis (taka) (mean) }\end{array}$ & $\begin{array}{l}\text { \% of daily income } \\
\text { spent on bidis }\end{array}$ & $\begin{array}{l}\% \text { of } \\
\text { respondents }\end{array}$ \\
\hline $51-100$ & 7.4 & 9.9 & 13.5 \\
$101-150$ & 7.9 & 6.4 & 26.6 \\
$151-200$ & 8.6 & 4.9 & 25.1 \\
$201-250$ & 7.7 & 3.4 & 16.2 \\
$251-300$ & 7.6 & 2.8 & 12.4 \\
$300+$ & 7.1 & 2.3 & 6.2 \\
Weighted average & 7.9 & 5.3 & \\
\hline
\end{tabular}

various other professions. Approximately two-thirds belonged to the age groups $26-35$ years and $36-50$ years $(37 \%$ and $33 \%$, respectively). ${ }^{\mathrm{x}}$

As shown in table 1, respondents in the lowest income group spent the highest proportion of their daily income on tobaccoalmost $10 \%$; the average proportion of daily income spent on bidis decreased as income increased. The low-middle income group spent the highest amount on bidis. The majority of the respondents spent $\$ 0.11-\$ 0.12$ (7.9-8.6 taka) per day or $\$ 3.45-$ $\$ 3.75$ (237-258 taka) per month on bidis. This finding is similar to other studies showing that the poor and disadvantaged consume more tobacco on average than do the rich, ${ }^{54-57}$ a finding particularly true with regards to bidis, the 'poor man's cigarette'.

Nationwide bidi expenditure was estimated using the quantitative survey results. The average daily bidi expenditure\$0.11 (7.9 taka) - was multiplied by the 10.1 million male bidi smokers estimated by the Global Adult Tobacco Survey, ${ }^{58}$ giving a total national bidi expenditure of approximately $\$ 1.1$ million per day. Extrapolated to $\$ 401.5$ million annually, this figure represents $0.4 \%$ of Bangladesh's GDP for 2010 of $\$ 105.4$ billion. ${ }^{59}$

\section{DISCUSSION}

A number of key issues arise from this study. Of particular interest is the question of how money currently spent on tobacco might better benefit the population. In addition to the obvious benefit of shifting tobacco spending to basic needs, there is the possibility that alternate employment might be generated for bidi workers from such redirected spending. At the simplest level, new job opportunities could arise to provide the additional products and services that people could afford in greater numbers if they were not spending money on bidis.

Given claims that increased tobacco taxes would cause job losses, it is useful to see, as a theoretical exercise, the number and type of alternate jobs that could be generated if people were to reduce their expenditures on bidis. The assumption in this discussion is that money previously spent on bidis would be redirected to basic needs. As shown in table 2, the amount currently spent annually on bidis in Bangladesh is equivalent to the price of 4.85 billion eggs, 291 million chickens, 1.46 million tons of rice, 2.91 million cows or 2.33 million cycle rickshaws. ${ }^{\mathrm{xi}}$ The amount is also enough to start more than one million small rural grocery shops. Money not spent on bidis could be used by customers to purchase goods at these new businesses.

\footnotetext{
${ }^{x}$ This roughly reflects the age dynamics within the overall population in 2011: $61 \%$ of Bangladeshis are aged between 15 and 64 years. ${ }^{53}$

xiThe totals are calculated using market prices as of November 2009: 6 taka per egg, 100 taka per $\mathrm{kg}$ of chicken, 20 taka per $\mathrm{kg}$ of rice, 10000 taka per cow, 12500 taka per rickshaw and 25000 taka to establish and stock a basic rural grocery shop. Rickshaws are both a popular vehicle in Bangladesh and one of the main earning sources for the poor.
} 
Table 2 Potential employment and nutrition sources if people stopped smoking bidis

\begin{tabular}{ll}
\hline Bidi smokers spend 29.12 billion & 1.46 million tonnes of rice \\
taka per year & 291 million chicken \\
& 2.91 million cows \\
& 4.85 billion eggs \\
& 2.33 million rickshaws \\
& 1.16 million small grocery shops \\
\hline
\end{tabular}

How many jobs could such alternative spending generate? This would depend on the degree to which bidi expenditures were reduced. However, the production of additional food to meet increased demand will either employ more farmers and farmhands or increase the output and income of existing farmers. Each new grocery shop could employ one to two people, meaning 1 to 2 million additional jobs. Similarly for rickshaws: as each provides employment for at least two people, more than 2 million jobs could be created. Each source of employment also has a multiplier effect: new jobs would be generated for those supplying goods and services to the small grocery shops or rickshaw pullers. Even if one assumes a total tobacco-related employment of 400000 persons, expenditure shifting could generate many times more jobs.

Consider also that a rickshaw puller, if he does not own his rickshaw, pays about $30 \%$ of his daily earnings to hire the rickshaw, meaning that he keeps $70 \%$ of what he generates, as opposed to the $4.6 \%$ kept by the bidi worker. Rickshaw pullers also work fewer hours per day and fewer days per week in less chemically hazardous conditions to earn a far higher salary than do bidi workers.

Tobacco cultivation and production is exceptional in the Bangladesh economy for the level of control exerted by the tobacco industry. Since most sectors of the Bangladeshi economy are not dominated by a few monopolistic companies, the likelihood is that new employment would both increase and allow workers to keep a far greater share of the revenue they generate. Food production in Bangladesh is not controlled by a few companies; produce farmers often choose where to sell their food while chicken farmers operate independently of corporate control. Thus, the share of profits going to food producers would be higher-and working conditions are likely to be less onerous, penurious and harmful-than bidi manufacturing or tobacco cultivation. At the same time, a significant portion of the Bangladeshi workforce is selfemployed and less susceptible to the abuses rampant in the tobacco industry. That other jobs would be considered more valuable is reinforced by a study ${ }^{29}$ finding that many boys producing bidis dream of one day becoming rickshaw pullers. Reduced tobacco use could contribute to a tremendous source of new and higher paid jobs, which in turn could also mean better health and nutrition for those currently engaged in bidi work or tobacco cultivation.

If these better employment possibilities were to generate significantly higher incomes, there could be a further multiplier effect throughout the economy, as the newly employed would make non-tobacco purchases that in turn would generate revenue for other low-income people. ${ }^{60}$ Expenditures by the low-income population mostly contribute to the local economy by creating local jobs, keeping money in the community, strengthening community investment capacity, creating more consumer choice through the operation of hundreds of small businesses and reducing ecological footprints through reduced long-distance transportation of goods. ${ }^{61}$ The results of this

\section{What this paper adds}

Several comprehensive studies conducted in low- and middleincome countries to analyse the tobacco industry's economic contribution argue that decreased tobacco consumption would not harm national economies, as increases in other sectors would offset financial losses in the tobacco sector. However, governments - particularly in lower income countries-continue to justify their unwillingness to take stronger steps against tobacco on concerns about job losses.

- This study suggests that the amount currently spent annually on bidis in Bangladesh is equivalent to the price of 4.85 billion eggs, 291 million chickens, 1.46 million tons of rice, 2.91 million cows or 2.33 million cycle rickshaws. If even a percentage of bidi expenditure were shifted to these other projects, none of which are controlled by a few monopolistic companies as is the tobacco sector, a large number of higher value, healthier and better remunerated jobs could be created, completely offsetting any job losses in the tobacco sector.

study echo previous studies, which show that a reduction in tobacco expenditure and reallocation of that spending to alternate goods and services may generate greater employment opportunities $^{22} 25-276263$ while improving living standards. ${ }^{64}$

Finally, we must consider the image of a steep pyramid where many people work to earn money for a few, versus a situation where people's efforts and monetary rewards are more closely related. Considering all the issues relating to the nature of bidi employment and remuneration and prospective alternate sources of employment, should bidi work continue to be considered as an important employment source in Bangladesh?

Acknowledgements A number of Bangladeshi local NGOs have made this research possible. In particular, we wish to thank UBINIG and the Social Advancement Forum, Kushtia; Organization of Rural Development, Meherpur; Bilchalon Development Service Center, Natore; Somadhan Songstha, Rangpur; AGAPA, Bandarban. Research assistants Abdullah Al Mahmud, Khairul Amin Khan Lumen, Aminul Islam Ripon and Kamal Ibne Amin Choudhury's contributions were exemplary. Support from WBB Trust members was most valuable; in particular, Syed Mahbubul Alam Tahin, Aminul Islam Sujon, Syeda Anonna Rahman, Kamrunnisa Munna and Ruhan Shama have provided their insights during various stages of the study.

Funding This study was funded by the Bloomberg Initiative to Reduce Tobacco Use (BI) through a grant from the International Union Against Tuberculosis and Lung Disease (The Union). Neither the BI nor The Union played any role in the design of this study, in the collection, analysis and interpretation of the data, in the writing of the report or in the decision to submit this paper for publication.

\section{Competing interests None.}

Ethics approval Like many other countries, Bangladesh does not yet have a human research ethics review board. All ethical issues involved in this project, including participant confidentiality, were carefully addressed by the researchers. This research project was constantly supervised by an ethnographer who received intensive ethics training at an Australian university. Despite the institutional deficiency in getting ethics approval, the researchers carefully followed all ethics protocols provided to them.

Contributors AR, DE and LJ wrote the article that was adapted from an original project report prepared by AR, RS and IA (Roy A et al. Tobacco-related poverty among farmers, workers and users in Bangladesh: a dismal present and little hope for the future. Unpublished project report). SA and SF provided technical input to the final article.

Provenance and peer review Not commissioned; externally peer reviewed.

\section{REFERENCES}

1. Tennant R. The American Cigarette Industry: a Study in Economic Analysis and Public Policy. New Haven, CT: Yale University Press, 1950. 
2. Tilley NM. Review of the American cigarette industry: a study in economic analysis and public policy by Richard B. Tennant. J Southern Hist 1951;17:278-9.

3. Efroymson D, Ahmed S, Townsend J, et al. Hungry for tobacco: an analysis of the economic impact of tobacco consumption on the poor in Bangladesh. Tob Control 2001;10:212-17.

4. John S. History and culture of bidis in India: production, employment, marketing and regulations. In: Asma S, Gupta P, eds. Bidi Smoking and Public Health. New Delhi: Ministry of Health and Family Welfare, Government of India, 2008:1-12.

5. Jha P, Chaloupka FJ, Moore J, et al. Tobacco addiction. In: Jamison DT, Breman JG, Measham AR, et al, eds. Disease Control Priorities in Developing Countries. Washington, DC: World Bank, 2006:869-86.

6. Frieden TR, Bloomberg MR. How to prevent 100 million deaths from tobacco. Lancet 2007;369:1758-61. PMID: 17512860.

7. Jha P. Curbing the Epidemic: Governments and the Economics of Tobacco Control. Washington, DC: World Bank, 1999.

8. Barnum H. The economic burden of the global trade in tobacco. Tob Control 1994:3:358-61.

9. Arunatilake N, Opatha M. The Economics of Tobacco in Sri Lanka. Economics of Tobacco Control Paper No. 12. Washington, DC: World Bank, 2003.

10. Warner K, Fulton G. Importance of tobacco to a country's economy: an appraisal of the tobacco industry's economic argument. Tob Control 1995;4:180-3.

11. Warner K. Tobacco taxation as health policy in the third world. Am J Public Health 1990;80:529-31.

12. Chapman S, Richardson J. Tobacco excise and declining tobacco consumption: the case of Papua New Guinea. Am J Public Health 1990;80:537-40.

13. Mao ZZ, Jiang JL, Gong ZP. Demand for cigarettes and pricing policy: a time-series analysis (in Chinese). Chinese Health Economics 1997:16:50-2

14. Van der Merwe R. The economics of tobacco control in South Africa. In: Abedian I van der Merwe R, Wilins N, et al, eds. The Economics of Tobacco Control: Towards an Optimal Policy Mix. Cape Town, South Africa: Applied Fiscal Research Centre, University of Cape Town, 1998:251-71.

15. Warner KE, Chaloupka FJ, Cook PJ, et al. Criteria for determining an optimal cigarette tax. Tob Control 1995:4:380-6.

16. Chaloupka FJ, Hu TW, Warner KE, et al. The taxation of tobacco products. In: Jha P, Chaloupka F, eds. Tobacco Control in Developing Countries. Oxford: Oxford University, 2000:237-72

17. Gallus S, Schiaffino A, La Vecchia C, et al. Price and cigarette consumption in Europe. Tob Control 2006;15:114-19.

18. Lancea PM, Akina JS, Dowb WH, et al. Is cigarette smoking in poorer nations highly sensitive to price? Evidence from Russia and China. J Health Econ 2004;23:173-89.

19. Chaloupka FJ, Wakefield M, Czart C. Taxing tobacco: the impact of tobacco taxes on cigarette smoking and other tobacco use. In: Rabin RL, Sugarman SD, eds. Regulating Tobacco. New York: Oxford University Press, 2001:39-71.

20. Fernández $\mathbf{E}$, Gallus $S$, Schiaffino $A$, et al. Price and consumption of tobacco in Spain over the period 1965-2000. Eur J Cancer Prev 2004;13:207-11.

21. Warner KE. The economics of tobacco: myths and realities. Tob Control 2000;9:78-89.

22. Chaloupka FJ, Warner KE. The economics of smoking. In: Anthony JC, Joseph PN, eds. Handbook of Health Economics Volume 1B. Oxford: North-Holland, 2000:1539-627.

23. Jha P. Analysis: avoidable global cancer deaths and total deaths from smoking. Nat Rev Cancer 2009;9:655-64.

24. Parvez S. Lobby backs bidi sector: health risks ignored. The Daily Star 2010. http:// www.thedailystar.net/newDesign/news-details.php?nid=141516 (accessed 11 Jan 2010)

25. Allen R. The False Dilemma: The Impact of Tobacco Control Policy on Employment in Canada. Ottawa, ON: National Campaign for Action on Tobacco, 1993.

26. Buck D, Godfrey C, Raw M, et al. Tobacco and Jobs: The Impact of Reducing Consumption on Employment in the UK. York: Society for the Study of Addiction and the Centre for Health Economics, University of York, 1995.

27. Van der Merwe R. The Implications of Falling Tobacco Consumption for Employment in South Africa: The Economics of Tobacco Control in South Africa. Cape Town: School of Economics, University of Cape Town, 1998

28. Dev R, Sujon Al. Tobacco farmers in Bangladesh: exploitation at the hand of the tobacco companies. In: Efroymson D, FitzGerald S, eds. Tobacco and Poverty: Observations from India and Bangladesh. Ottawa ON: PATH Canada, 2002:24-9.

29. Blanchet T. Child Work in the Bidi Industry. Dhaka: UNICEF, 2000.

30. Blanchet T, Biswas H. Child Labour in Bidi Factories (Kushtia District). Dhaka: Radda Barnen, 1998.

31. Shamim I. Child Exploitation in Cigarette Factories. Dhaka: Bangladesh Shishu Adhikar Forum, 1993

32. Bangladesh Bureau of Statistics. Statistical Pocketbook of Bangladesh 2008 Dhaka: BBS, 2009.

33. United Nations Population Fund. The State of the World Population 2009. New York: UNPFA, 2009

34. Bangladesh Bureau of Statistics. Report on Monitoring of Employment Survey 2009. Dhaka: BBS, 2010. http://www.bbs.gov.bd/WebTestApplication/userfiles/ Image/Latest\%20Statistics\%20Release/employsurvey 09.pdf (accessed 5 Jan 2010).
35. Bernard HR. Research Methods in Anthropology: Qualitative and Quantitative Approaches. Lanham: Altamira Press, 2006.

36. Ahmed S, Rahman A, Hull S. Use of betel quid and cigarettes among Bangladesh patients in an inner-city practice: prevalence and knowledge of health effects. $\mathrm{Br} J$ Gen Pract 1997; 47:431-4.

37. Ali Z, Rahman A, Rahman T. Appetite for Nicotine: An Economic Analysis of Tobacco Control in Bangladesh. Economics of Tobacco Control Paper No. 16. Washington DC: World Bank, 2003

38. OANDA. Historical Exchange Rates. http://www.oanda.com/currency/historical-rates (accessed 18 May 2011).

39. Panchamukhi PR, Woollery T, Nayanatara SN. Economics of bidis in India. In: Asma S, Gupta P, eds. Bidi Smoking and Public Health. New Delhi: Ministry of Health and Family Welfare, Government of India, 2008:167-95.

40. Voluntary Health Association of India. Caught in a Death Trap: The Story of Bid Rollers of West Bengal and Gujarat. New Delhi: VHAl, 2008.

41. Waring M. If Women Counted: A New Feminist Economics. San Francisco: Harpe Collins Publishers, 1990.

42. Roy A. A walk on the dark side: shedding light on tobacco-related employment. In: Efroymson D, Jones L, FitzGerald S, eds. Sometimes We Win: Tobacco Control Success Stories from Asia. Ottawa ON: HealthBridge, 2010:103-10.

43. Rahman M. Health hazards and quality of life of the workers in tobacco industries: study from three selected tobacco industries at Gangachara Thana in Rangpur District of Bangladesh. Int J Epidemiol 2009;6. http://www.ispub.com/ostia/index. php?xmIPrinter $=$ true\&xmlFilePath=journals/ije/vol6n2/tobacco.xml laccessed 18 May 2011)

44. Koli PP. Socio-economic condition of female bidi workers in Solapur District. Social Change 1990;20:76-81.

45. Mohandas M. Bidi workers in Kerala: conditions of life \& work. EPW 1980;15:1517-23. http://www.jstor.org/stable/4369052.

46. Sudarshan R, Kaur R. The tobacco industry and women's employment: old concerns and new imperatives. Indian J Labour Econ 1999;42:675-85.

47. Kumar A. International labor organization action project to promote 'decent work. In: de Beyer J, Gupta N, Gupta P, et al, eds. Tobacco Research in India: Proceedings of an Expert Meeting on Supporting Efforts to Reduce Harm. Mumbai: Tata Institute of Fundamental Research, 2003.

48. Gupta PC, ed. Bidi Smoking and Public Health. New Delhi: Ministry of Health and Family Welfare (Government of India), 2008.

49. Swami S, Suryakar AN, Katkam RV, et al. Absorption of nicotine induces oxidative stress among bidi workers. Indian J Pub Health 2006;50:231-5.

50. Chattopadhyay BP, Kundu S, Mahata A, et al. A study to assess respiratory impairments among male beedi workers in unorganized sectors. Indian J Occup Environ Health 2006;10:69-73

51. Govekar RB, Bhisey RA. Elevated urinary thioether excretion among bidi rollers exposed occupationally to processed tobacco. Int Arch Occup Environ Health 1992;64:101-4.

52. Gopal M. Health of women workers in the beedi industry. Medico Friends Circle Bulletin Jan-Feb 2000;268-269:1-6.

53. Central Intelligence Agency. The World Factbook. https://www.cia.gov/library/ publications/the-world-factbook/geos/bg.html (accessed 18 May 2011).

54. Bobak M, Jha P, Nguyen S, et al. Poverty and smoking. In: Jha P, Chaloupka FJ, eds. Tobacco Control in Developing Countries. Oxford: Oxford University Press, 2000:41-61.

55. Sorensen G, Gupta PC, Pednekar MS. Social disparities in tobacco use in Mumbai India: the roles of occupation, education, and gender. Am J Public Health 2005:95:1003-8

56. Naher F, Efroymson D. Addressing Tobacco and Poverty in Bangladesh: Research and Recommendations on Agriculture and Taxes. Dhaka: WBB Trust-HealthBridge, 2007.

57. Graham H. When Life's a Drag: Women, Smoking and Disadvantage. Norwich: HMSO, 1994.

58. World Health Organization. Global Adult Tobacco Survey: Bangladesh Report 2009. Dhaka: WHO, 2009

59. Global Finance. Bangladesh Country Report. http://www.gfmag.com/gdp-datacountry-reports/321-bangladesh-gdp-country-report.html\#axzz1MbssvTyT (accessed 18 May 2011).

60. Shuman MH. Going Local: Creating Self-Reliant Communities in a Global Age .New York: The Free Press, 1998

61. Robinson N, LaMore RL. Why Buy Local? An Assessment of the Economic Advantages of Shopping at Locally Owned Businesses. Michigan: Center for Community and Economic Development, Michigan State University, 2010.

62. Warner K, Fulton G. The economic implications of tobacco product sales in a nontobacco state. JAMA 1994;271:771-6.

63. Warner K, Fulton G, Nicolas $P$, et al. Employment implications of declining tobacco product sales for the regional economies of the United States. JAMA 1996;275:1241-6.

64. Hu TW, Mao Z, Liu Y, et al. Smoking, standard of living, and poverty in China. Tob Control 2005:14:247-50. 